\title{
EL CATALÀ EN ELS MITJANS DE COMUNICACIÓ
}

\author{
Albert Rico i Busquets
}

Llengua i mèdia

Universitat Autònoma de Barcelona ${ }^{1}$

\section{INTRODUCCIÓ}

En aquest article parlarem dels problemes que es plantegen en l'elaboració d'un model de llengua oral formal del català, a partir del moment en què aquesta llengua accedeix als mitjans de comunicació audiovisuals, molt tímidament a partir de la dècada dels 60 , amb certa energia a mitjan dècada dels 70 i amb força en la dècada dels 80 .

\section{Algunes PRECISIONS SOBRE EL CONCEPTE DE «MODEL" DE LlENGUA}

Entenem per "model de llengua" un conjunt de recursos (fonètics, morfosintàctics, lèxics, discursius) que obtenim del sistema lingüístic, per satisfer unes necessitats comunicatives noves que es presenten en un moment determinat. Així, l'aparició dels mitjans de radiodifusió introdueix una situació comunicativa nova, a partir de la circumstància en què un emissor podrà adreçar-se, de manera simultània, a una audiència físicament absent, i a partir de les enormes possibilitats comunicatives que permet aquesta situació: retransmissions que amplifiquen l'audiència de registres o gèneres existents (teatre, música, etc.), però també noticiaris, informacions diverses, teatre radiat, entrevistes, reportatges, etc.

Aquest model no està fixat prèviament, i s'ha d'inspirar lògicament en els models referencials existents, tant els relatius a la llengua oral (teatre) com a l'escrita (premsa, literatura). Per tant podem dir que el model s'anirà conformant a mesura que les noves circumstàncies d'ús vagin creixent i donant lloc

1. Llengua i mèdia (http://kane.uab.es/llenguaimedia/), grup de recerca consolidat de la Universitat Autònoma de Barcelona. 
als diversos gèneres radiofònics, que exigiran recursos lingüístics i discursius nous. Tampoc no es tracta d'un model únic (o uniforme): el sistema ofereix possibilitats diverses que els agents implicats en el desenvolupament del nou àmbit comunicatiu utilitzaran en legítima competència. L'èxit o el fracàs de les diverses opcions anirà perfilant les línies generals del model en qüestió.

\subsection{L'audiència i la percepció del model}

Quan parlem d'un model lingüístic per als mitjans de comunicació ens enfrontem alhora a diversos aspectes del llenguatge: fonètica, morfologia, sintaxi, lèxic, discurs..., i no tots aquests aspectes són percebuts de la mateixa manera pel receptor.

En primer lloc, la fonètica i l'elocució en general. Lògicament, és el factor més destacat, perquè és el que es nota més, l'immediatament perceptible, el que fa que es reconegui a primer cop d'ull la competència lingüística d'un locutor (si és catalanoparlant d'origen, o si és d'origen castellanòfon, per exemple). A més, aquesta percepció és intuïtiva, forma part de la competència lingüística del catalanoparlant.

En segon lloc, el lèxic. Qualsevol parlant, per poc competent que sigui, pot distingir el lèxic propi de la seva llengua del que no ho és (interferències històriques, al marge).

En tercer lloc, la morfologia i la sintaxi, que poden passar més desapercebudes — sobretot la sintaxi- a l'oient que no té una mínima formació, perquè les estructures lingüístiques de dues llengües romàniques, i més si han estat en contacte durant tants anys, tenen molts punts en comú.

En darrer lloc, els elements relacionats amb les característiques del discurs: longitud de la frase, dislocacions i focalitzacions, densitat informativa, etc., que són percebuts més directament pels experts, des del punt de vista tècnic, però que els destinataris reben com un element més de l'efecte comunicatiu, amb la veu, l'entonació, el contingut del missatge, etc.

\section{El CATALÀ I ELS INICIS DE LA RADIOFONIA}

Les primeres emissores radiofòniques aniran apareixent a mitjan dècada dels anys 20, en plena dictadura de Primo de Rivera, a iniciativa de les unions de radiooients (Franquet 2001: 27-116). La primera de tot l'estat fou Radio Barcelona, EAJ-1, el novembre de l'any 1924, impulsada per una associació de radiooients, l'Asociación Nacional de Radiodifusión, creada el febrer d'aquell mateix any. I el 1925 naixia Radio Catalana (EAJ-13), que va tenir 
una vida breu (vid. Franquet 2001: 46-47). Aquestes dues emissores emetien en castellà; en plena dictadura de Primo de Rivera, era difícil que es plantegessin usar el català. Sembla, però, que s'hi havia permès radiar algunes obres de teatre en aquesta llengua (Franquet 2001: 102) ${ }^{2}$.

L'any 1926 Radio Barcelona es fusiona amb Unión Radio de Madrid, que pretenia crear una xarxa d'emissores d'abast estatal. La fusió va provocar el trencament amb l'Asociación Nacional de Radiodifusión, promotora de l'emissora degana, que va demanar una nova concessió, atorgada el 26 de març del 1930, amb el nom de Ràdio Associació de Catalunya, que des del principi va usar exclusivament el català en la programació 3 .

Amb la República la societat i la política van recuperar el protagonisme i la ràdio hi va tenir un paper molt important. Creixen les hores d'emissió i la varietat de programes. Es retransmeten en directe esdeveniments polítics com la proclamació de la República o els fets d'octubre, durant els quals el president Companys s'adreçarà als ciutadans per les dues emissores de la ciutat (Franquet 2001: 91-92). Pel que fa a l'ús del català, Ràdio Associació de Catalunya competeix amb Radio Barcelona per la mateixa audiència, i el seu caràcter diferencial és, precisament, l'ús exclusiu d'aquesta llengua. Això empeny Ràdio Barcelona a incloure-la també en les seves emissions, en una proporció que va arribar a ser de 3 a 1 a favor del català (Franquet 2001: 103). Les noves emissores que s'aniran installant a les principals ciutats de Catalunya també faran servir preferentment el català ${ }^{4}$.

Aquest període es va cloure de forma dramàtica amb la victòria de les tropes franquistes i la prohibició de l'ús públic de la llengua catalana en tots els àmbits. Ràdio Associació de Catalunya va passar a ser Radio España de Barcelona 5 .

2. En els primers anys hi havia molt poques hores de programació, bàsicament retransmissions de concerts en directe, butlletins meteorològics i informació borsària.

3. "L'EAJ-15 es dedicarà "a expandir la cultura, la música i la literatura d'un poble, conscients de la responsabilitat que pesa al seu damunt" (Catalunya Ràdio. 14, 6 d'agost de 1932, p. 3). Cit. per Franquet (2001: 102).

4. Les ciutats més importants de Catalunya inauguren emissores pròpies en aquesta època: Tarragona, Girona i Lleida, les capitals de província, però també Terrassa, Sabadell, Reus, Vilanova, Manresa i Vilanova i la Geltrú.

5. Un dels primers objectius de les tropes ocupants fou conquerir "para España esa emisora catalana separatista" (...) Aquesta especial consideració convertia Ràdio Associació de Catalunya en un preat trofeu, per la qual cosa un grup de soldats es va dirigir ràpidament cap als estudis de l'emissora. La locutora Rosalia Rovira, que anunciava en català un disc, va ser interompuda...: "Sí, señorita: digo que ahora, el nombre de la emisora, a ese 'Aqui Radio Asociación de Cataluña' que usted va a pronunciar, debe, tiene que añadir 'al servicio de España y a las órdenes del Caudillo'; $y$ antes de que ella se acercase al micrófono, antes de que pudiera reaccionar, un "Arriba España", "Viva Franco!", gritando ante el mismo, daba al mundo la noticia de que Radio Asociación de Cataluña hablaría ya para siempre el lenguaje Nacional, que Barcelona era nuestra" (Radio Nacional 21, 2 d'abril de 1939, p. 5). (Cit. per Franquet 2001: 127-128). 


\subsection{El model de llengua de la ràdio de la República $i$ el model de Fabra}

Lamentablement, no tenim gaire informació sobre el model de llengua que es vehiculava en els programes dels anys trenta. Sabem que n'hi havia de dedicats a la llengua i que Ràdio Associació concedia molta importància a l'ensenyament del català, amb lliçons de gramàtica i programes infantils per a la correcció de barbarismes. A Ràdio Barcelona, aprofitant la gran popularitat del locutor Toresky i el seu personatge infantil, Miliu, emetien un programa de llengua en forma de converses, en què els personatges radiofònics eren corregits implacablement pel professor Artur Balot, que n'era el guionista (vid. Solà 1977: 107-109). Al seu torn, Ràdio Associació emetia programes en què es feien lliçons de gramàtica catalana, i altres d'específicament dedicats als infants, per corregir barbarismes (Franquet 1986: 153).

Sí que sabem, però, que hi havia un model per a la llengua escrita, el model de Fabra i l'Institut d'Estudis Catalans, l'anomenat "català literari". A principis de segle Pompeu Fabra havia impulsat una reforma ortogràfica i gramatical que havia establert les bases d'un català modern. La feliç conjunció entre un poder polític embrionari, la Mancomunitat de Diputacions, dirigida eficaçment per Prat de la Riba, i la competència de Fabra i els seus col-laboradors (cf. Balcells \& Pujol 2002) va donar els seus fruits. A redós de la Secció Filològica de l'IEC, creada el 1911, el 1913 foren promulgades les Normes ortogràfiques, seguides del Diccionari ortogràfic, el 1917, de la Gramàtica catalana, el 1918, i del Diccionari, el 1932. Aquesta empresa es complementava amb manuals de divulgació (Ortografia catalana, Les principals faltes de gramàtica, Diccionari ortogràfic abreujat i La conjugació dels verbs catalans), a més de la intervenció regular del mateix Fabra en la premsa, per difondre el model de català literari, en petits articles de divulgació a $L a P u$ blicitat, posteriorment publicats amb el nom de "Converses filològiques".

Aquest projecte pretenia conformar una varietat de llengua referencial ${ }^{6}$, depurada de castellanismes i dialectalismes, amb una ortografia unificada, en la qual es podien sentir reconeguts tots els dialectes, i que havia de servir adequadament sobretot per als usos formals. Però Fabra pensava sobretot en la llengua escrita, en l'esmentat "català literari". Pel que fa a la llengua oral, tenia una idea clara de la pronunciació genuïna del català i no vacillava a fustigar el que en considerava desviacions, sobretot les del parlar de Barcelona, de tanta importància en la formació de la llengua literària pel pes de-

6. "(...) entenent com a tal [llengua referencial] la varietat codificada d'una llengua que serveix de base als llenguatges especialitzats i de model de prestigi a totes les altres varietats." (Lamuela \& Murgades 1984: 12). 
mogràfic i cultural de la ciutat, però no tenim un equivalent a l'ortografia fabriana en el terreny de l'ortoèpia.

L'aparició de la radiodifusió en català, els anys 30, aparentment no va desvetllar un interès per fixar un model específic de llengua. La idea de variació funcional, d'adequació de la llengua a les diverses circumstàncies d'ús, que es desenvolupa modernament a partir de Gregory \& Carrol (1978) ${ }^{7}$, està molt allunyada de les preocupacions de l'època. En aquell temps la distinció "llengua correcta" / "llengua incorrecta" és l'essencial, i s'aplica a qualsevol registre. Això no vol dir que els professionals conscients no es plantegin l'adequació de la llengua als nous gèneres. Per exemple, els professionals de la radiodifusió es van preocupar molt per les característiques del teatre radiat, que no podia ser el mateix que la retransmissió d'una obra de teatre. Fins i tot es van arribar a convocar concursos que es justificaven pel caràcter diferent d'aquest nou gènere literari, el qual havia de tenir en compte la imaginació, la suggestió auditiva, etc. (Franquet 1986: 154).

Podem especular que el català parlat d'aleshores es devia basar en els usos formals tradicionals, el teatre, l'oratòria política, i sobretot en el model de català literari. Així ho apunten les esmentades lliçons de llengua que programava Ràdio Barcelona. D'altra banda, l'ús secular de la llengua, sobretot en àmbits formals, va conformant una tradició que s'incorpora a la competència lingüística del parlant i l'orienta sobre determinades qüestions, especialment pel que fa a la fonètica i al lèxic (v. 1.1). A partir d'aquí es podria començar a construir un model que amb el temps s'hauria d'anar polint.

Després de la desfeta republicana, l'any 1939, el català va quedar proscrit de la vida pública. La llengua per a usos formals passava a ser exclusivament el castellà, en tots els àmbits: educació, Església, Administració i mitjans de comunicació (cf. Benet 1995).

\section{El lLarg CAmí Per escoltar la veu PRÒPIA: 1939-1975}

\subsection{La ràdio}

La política del franquisme pel que fa a la presència de la llengua catalana a la ràdio no va mantenir sempre la mateixa rigidesa. El català va anar traient el cap, primer en emissores locals, menys sotmeses a la censura, en forma de comentaris o d'expressions deixades anar de forma casual, de difícil control en un mitjà com el radiofònic. L'any 1950 es va transmetre la primera obra de tea-

7. Per al català, l'obra pionera és la de Lluís López del Castillo (1976). 
tre en català de la postguerra, El pati blau, de Santiago Rusiñol, per Radio Nacional de España en Barcelona, i al llarg d'aquesta dècada es dóna protagonisme a les retransmissions de sardanes, a concerts de música popular, etc. El marc i la intenció d'aquests programes és el foment de la "sana" tradició i el folklore popular. De fet, encara que a partir de principis dels anys 70 hi ha un augment de programes en català, fins i tot d'algun d'informatiu o de temes d'actualitat, no serà fins a la mort del dictador que les emissores radiofòniques no es prendran seriosament la presència del català en antena.

\subsection{La televisió}

L'any 1956 s'inaugura TVE als estudis del passeig de la Habana, a Madrid. I el 1959 s'estableix l'enllaç hertzià entre la capital de l'estat i Barcelona. La seu de TVE a Barcelona s'installla a l'Hotel Miramar, que esdevindrà un centre de producció de programes.

En aquesta nova situació, s'obria una escletxa per emetre en català, aprofitant les possibilitats de desconnexió de la xarxa general. De 1964 a 1967 se n'emetia una hora setmanal, en concret una obra de teatre. La primera fou La ferida lluminosa, de Josep Maria de Sagarra. Després, lentament, es va anar ampliant l'horari d'emissió, sempre en franges de migdia i a primera hora de la tarda, amb una cobertura que arribava a les Illes Balears, però no al País Valencià.

L'any 1967 es produeix "Mare Nostrum", el segon programa en català en la història de la televisió. Era "una mena de revista de temes pintorescos del Principat i les Illes que evitava qualsevol qüestió polèmica”. L’any 1973 apareix el primer programa amb contingut ideològic, que tracta temes polèmics, "Giravolt". En aquella època RTVE a Catalunya emet tres hores diàries en català. I el 1974 s'hi emet el primer informatiu televisiu, "Miramar"8.

\section{Aprofitant les escletxes, Però ¿AMB Quin MOdel?}

Els encarregats de cobrir aquestes primeres escletxes que ofereixen els mitjans radiofònics i audiovisuals són locutors i professionals que treballen en castellà en aquests mateixos mitjans, en emissores locals o de Barcelona, i que tenen el català com a llengua familiar o col-loquial ${ }^{9}$. La seva llengua professio-

8. http://www.rtve.es/tve/b/catalunya/comunicacion/historia.htm (20-XI-2007).

9. També s'encarreguen programes, en especial per a la televisió, a personalitats de la vida literària, com Montserrat Roig, Maria Aurèlia Capmany, Robert Saladrigues o Terenci Moix. 
nal havia sigut el castellà —i ho continuaria sent—; havien estudiat a l'escola i la universitat en castellà, llegien habitualment en castellà ${ }^{10}$, i a més a més la gran majoria no havien tingut accés a cap instrucció en català escrit. La llengua que coneixien era la informal, amb girs, construccions i lèxic poc adequats per a un registre formal, en el millor dels casos, i molt interferits pel castellà, en el pitjor. A més a més, en la seva feina se'ls havia exigit eliminar qualsevol rastre de fonètica vernacular: "locutors i actors han de tenir una pronúncia impecable i correcta en castellà. (...) han de dominar el castellà de manera perfecta i eradicar qualsevol record d'accent autòcton" (Franquet 2001: 212).

Però es tracta d'aprofitar els recursos amb el mínim cost econòmic. Quan RTVE decideix dedicar unes quantes hores setmanals a l'emissió de programació en català, els professionals catalans del centre que participen en el projecte han de servir-se de la llengua en un registre que els resulta poc o gens habitual.

Els locutors i actors procuraven ajustar-se al model que existia en català, el de la llengua literària, el model de Fabra. En ocasions disposaven de l'ajut de correctors (a RTVE), que podien intervenir en els textos preparats per ser llegits, però no en els més o menys improvisats. En el cas dels programes conduits per collaboradors externs, aquests provenien del món de la literatura i, per tant, també resulta evident que estaven familiaritzats amb el registre formal literari.

\subsection{El paper dels correctors}

Durant la dictadura franquista, la transmissió del coneixement del català escrit (ortografia, gramàtica) es va produir en circuits no regulats, més o menys clandestinament. Bandejada la llengua del sistema educatiu, només quedava el recurs de les classes particulars, celebrades discretament en domicilis privats, amb pocs assistents i plens de bona voluntat.

L'altra manera de transmetre un cert coneixement de la llengua, a partir de les publicacions periòdiques, era també molt precària. Es publicava molt poc en català i el que es publicava tenia poca difusió. A més, la majoria de catalanoparlants no estaven acostumats a llegir en català, i la idea del que era correcte $\mathrm{o}$ incorrecte quedava difuminada ${ }^{11}$. En aquestes circumstàncies

10. Hi havia molt poques revistes de difusió general en català: Serra d'Or, vinculada a l'abadia de Montserrat, o Oriflama, al bisbat de Vic, totes dues de periodicitat mensual. Hi hagué un intent d'editar un setmanari, Tele-estel (1966), a l'empara de la Llei de premsa de Fraga Iribarne (III 1966), que va patir una suspensió temporal l'any 1969, i definitiva el 1970.

11. En cas de dubte, es preferia la paraula més allunyada del castellà. 
era possible que un petit grup de correctors, amb criteris més o menys uniformes, sorgits dels mateixos mestratges, poguessin orientar el model de llengua en una direcció determinada. Es pot dir que no hi ha text d'abans dels anys 70 que no es publiqui sense passar abans pel control d'un corrector. De manera que fins i tot escriptors unànimement lloats pel seu estil, com Josep Pla, sotmetien els seus textos a la correcció ${ }^{12}$.

Els criteris amb què els correctors aplicaven el model de català literari de Fabra eren restrictius. En una situació precària, com la d'aleshores, es tractava de resistir, la llengua estava a la defensiva. I tampoc no hem d'oblidar que la institució que havia de vetllar pel manteniment de la norma, pel model de llengua, l'Institut d'Estudis Catalans, vegetava en les catacumbes o en la semiclandestinitat ${ }^{13}$. En aquestes circumstàncies tan difícils, la immigració hispanòfona dels anys seixanta representaria una pressió afegida per a l'ús de la llengua col·loquial.

En aquest model de llengua els correctors optaven sempre per les possibilitats del sistema que resultaven més allunyades del castellà i/o de la llengua parlada, fins i tot en els casos en què la "doctrina" de Fabra no ho avalava. Per exemple, preferien el perfet simple al perifràstic, els plurals arcaics (boigs, boscs, texts) als col-loquials, que també eren normatius (bojos, boscos, textos), les construccions amb el relatiu compost el qual, el possessiu arcaic llur, llurs, etc., i recorrien a formes que ja no eren vives a la llengua parlada: àdhuc ('a més a més'), quelcom ('alguna cosa'), tanmateix ('però', 'en canvi'), etc. La influència d'aquests correctors, en cercles més o menys amplis, feia que s'identifiqués el "català correcte" amb les opcions esmentades, i la situació sociolingüística de la llengua no ajudava a aclarir equívocs ${ }^{14}$.

Quan aquests correctors, o aquesta "escola de correctors" té ocasió de treballar en un mitjà audiovisual (o radiofònic) hi apliquen criteris similars. I també pot passar que siguin els professionals mateix els que recorren a aquestes solucions espontàniament, amb la idea que són "més correctes". Així, llur, àdhuc (pronunciat sovint adbuc), quelcom, etc., conviuen amb construccions interferides com tenir que, degut a que, etc.

Aquest serà, en línies generals, el model del català en els mitjans de comunicació durant el període predemocràtic: basat en una "tradició" restrictiva, en la "intuïció" dels locutors (mediatitzada per aquesta tradició), en la

12. Si bé és cert que el corrector de Pla, Bartomeu Bardagí, afirmava que a Pla calia corregir-li "Ben poques coses. Bàsicament era correcte. La consciència lingüistica era formidable (...)". Cit. per Mir (2003: 222)

13. Fins a l'any 1976 no fou reconegut oficialment (RD 3118/1976, de 26 de novembre)

14. Aquesta actitud dels correctors va provocar polèmiques virulentes, circumscrites a l'àmbit de les publicacions en català dels anys 60, sobretot a Serra d'Or. Eren molt crítics amb l'actitud dels correctors Joan Fuster, Terenci Moix i Maria Aurèlia Capmany, entre d'altres. 
llengua escrita, i amb la intervenció dels correctors, quan el pressupost ho permetia.

No hi ha estudis que permetin conèixer com reaccionava l'audiència enfront d'aquest model. La programació era limitada i l'audiència també, i era una audiència també influïda per les qüestions que acabem d'esmentar. A més, la situació repressiva feia poc recomanable qüestionar el model.

\section{ELS PRIMERS ANYS DE L’ETAPA DEMOCRÀTICA.}

\subsection{La ràdio}

El canvi en la situació política de l'estat espanyol repercutia també en l'àmbit de la radiodifusió, sensible a les demandes de la societat catalana (Franquet 2001: 213-219). En aquesta època es produeix un increment substancial de la programació en català, molt important en les emissores locals, però també en les d'àmbit estatal. En el cas de Radio Nacional de España, l'increment de la programació en català en les dues emissores de Barcelona provocava problemes de coordinació amb la programació estatal. La solució va ser crear una nova emissora, la primera que emetia tota la programació en català, a finals de 1976, Ràdio 4 (Munsó 1980: 15ss).

\subsection{La televisió}

La producció en català del circuit de RTVE continua creixent, en franges de migdia, tarda i nit, amb alguna desconnexió del circuit estatal, on continua la programació en castellà. A partir del 1976 es presenta un programa de llengua, "Català amb nosaltres", centrat en la correcció normativa i en la diversitat dialectal. Apareix "Miramar esportiu", el primer programa d'esports en català. S'emet per primera vegada una pel-lícula de ficció filmada en escenaris naturals, Un somni i mil enganyifes, i s'enregistra la primera producció dramàtica en color, Hamlet, en versió de Terenci Moix. En cinc anys (1978-1983) el circuit passa de 68 a 83 hores mensuals d'emissió.

El 1992 el circuit català de televisió (TVE) serà l'encarregat de transmetre, amb TV3, Televisió de Catalunya (canal 33), els Jocs Olímpics de Barcelona.

En els darrers anys s'ha produit un declivi dels centres regionals de RTVE, relacionada amb la crisi econòmica de l'ens, que s'ha vist agreujada per la competència de les cadenes privades. Això ha comportat la reducció dels centres regionals en general, i del de Sant Cugat (seu actual del centre 
de RTVE a Catalunya) en particular, amb reducció també de la producció pròpia. La crisi també afecta Radio-4, la primera emissora que va tenir una programació íntegrament en català, i que està amenaçada de tancament.

Però el veritable canvi en la producció televisiva no es produirà fins el 1983, amb la creació de la Corporació Catalana de Ràdio i Televisió.

\subsection{Els models}

Tant a la ràdio (fonamentalment Ràdio 4) com a la televisió es manté el model que hem comentat (v. 4.1), tot i que l'ampliació de l'oferta genera necessitats noves. El control lingüístic es manté sobretot en els informatius, però en altres casos el relaxament és evident. Es continua produint una barreja entre el model del català literari i les interferències més estridents.

Mentrestant, en el panorama comunicatiu català es produeixen novetats, que a la llarga hauran d'afectar els mitjans audiovisuals. L'any 1976 apareix als quioscos el diari Avui, el primer periòdic diari des d'abans de la guerra ${ }^{15}$. En l'elaboració del producte tindran un paper essencial els correctors, perquè els periodistes de l'època no havien rebut cap mena de formació en llengua catalana, al marge de la que s'haguessin pogut procurar personalment, i els impulsors de la publicació pretenien que tingués un paper pedagògic en el procés de normalització lingüística, que tot just començava a plantejar-se. El model de llengua que s'aplicava era el mateix que hem comentat (4.1): preferència per les formes més "genuïnes" en lèxic i en morfologia (o sigui, més allunyades del castellà i de la llengua col·loquial).

Però en el món de la correcció s'havia produit un fet important. El 1975 s`havia graduat la primera promoció de llicenciats en filologia catalana per la Universitat de Barcelona. Una lleva de lingüistes amb formació universitària, joves... i amb criteris diferents pel que fa al model de llengua dels mitjans de comunicació. En l'elaboració del diari xocaven el criteri "tradicional" de la correcció amb una posició, que s'aniria perfilant més endavant, i que estava a favor de "modernitzar" la llengua ${ }^{16}$ (V. infra).

Aquesta posició es va anar manifestant en diaris i revistes ${ }^{17}$ i va adquirir certa virulència ${ }^{18}$. Ha passat a la història amb el nom de "polèmica heavys ligths", que és com la va batejar un periodista de l'època.

15. L'any 1937 es publicaven a Barcelona una dotzena de diaris, set dels quals eren en llengua catalana.

16. Un dels primers articles en defensa d'un nou model és el de Ricard Fité, titulat precisament "Volem una llengua moderna".

17. Crònica, Ciència, El Món...

18. Per a un seguiment de la polèmica, v. Casals (2001a). 


\section{LA CONSOlidACIÓ DELS MITJANS DE COMUNICACIÓ EN CATALÀ}

El fet més rellevant per als mitjans de comunicació en català i, correlativament, per a la gestació d'un model de llengua, és la creació de la Corporació Catalana de Radio i Televisió (CCRT), que posarà en marxa la primera televisió i una xarxa d'emissores que havien de revolucionar el panorama audiovisual.

El 26 de juliol de 1983 s'emet la primera notícia per antena a Catalunya Ràdio: la mort de Charlie Rivel, i s'inicien els butlletins horaris i els informatius; a l'octubre comença la programació regular. L'11 de setembre té lloc la primera emissió experimental de TV3 i el gener de 1984 comença la programació regular, amb una cobertura del 80\% del territori i el $90 \%$ de la població. En anys successius aniran creant-se noves emissores de la xarxa: Catalunya música (1987), Canal 33 (1988), Catalunya cultura (1999), Canal 3/24 (només notícies, 2003) i IcatFM (ràdio i internet, 2006).

L'envergadura del projecte de la CCRT desbordava la situació dels mitjans de comunicació audiovisuals. Hi havia recursos econòmics, mitjans tècnics i humans; hi havia un projecte nacional. Una de les tasques d'aquest projecte, bàsica, era contribuir a la normalització lingüística; per tant, el model de llengua era una qüestió fonamental.

\section{CAP A UN MODEL NOU}

Com hem dit més amunt, arran de l'aparició del diari Avui es va anar perfilant una posició, sobretot entre els lingüistes joves que feien tasques de correcció, en el sentit que el model de llengua reduccionista i encarcarat que havia predominat fins aleshores en la premsa i en els mitjans audiovisuals (en especial TVE i Ràdio 4) no era vàlid ${ }^{19}$.

Aquest grup de correctors propugnaven un model més acostat a la llengua "del carrer", que els lectors (en el cas de l'Avui) poguessin sentir-se identificats amb el que llegien; es decantaven per la varietat central barcelonina, perquè era natural — deien — basar-se en la varietat parlada per un major nombre de persones. Per aconseguir-lo proposaven bandejar de l'estàndard (escrit o oral) els arcaismes i els dialectalismes, i estaven a favor de donar entrada a paraules que, tot i no figurar al diccionari normatiu, tenien

19. Entre els membres més significatius d'aquest grup, que posteriorment es va constituir en "Grup d'estudis catalans", trobem Xavier Pericay (autor del llibre d'estil del Diari de Barcelona), Ferran Toutain, Ricard Fité (autor del llibre d'estil de l'Avui i d'El Periódico) i Oriol Camps (director d'Ésadir, portal lingüístic de la Corporació catalana de mitjans audiovisuals). 
tradició en la llengua (els anomenaven "castellanismes històrics") i d'altres que, simplement, eren tan esteses que semblava impossible substituir-les per alternatives genuïnament catalanes. Al costat d'això, optaven per les variants morfològiques més acostades a la llengua parlada (perfet perifràstic i plurals en -os, enfront del perfet simple i els plurals en $-s$, etc.).

Els plantejaments d'aquest grup de lingüistes van tenir ocasió de plasmar-se per escrit en el manual d'estil del Diari de Barcelona, un periòdic de llarga història, fundat el 1792 — era el degà de la premsa continental. L'Ajuntament de Barcelona va adquirir el diari, l'any 1985, i el va cedir al Grup Zeta, perquè l'edités en català. La responsabilitat lingüística de l'empresa fou encomanada a Xavier Pericay, un dels més conspicus representants de les posicions "ligth".

Per una altra banda teníem els correctors (i lingüistes) partidaris del model fabrià més estricte, de les solucions més genuïnes, en nom del patriotisme i de la defensa de la llengua, que acusaven els "light" d'espanyolistes.

Una tercera posició la representaven els departaments de llengua d'unes quantes universitats catalanes "perifèriques", que criticaven la pobresa del model "ligth", perquè ignorava les solucions que podia aportar el diasistema. A més a més, alertava sobre el fet que donar com a referència en els mitjans audiovisuals un model basat en una única varietat podia provocar que els parlants de les varietats menystingudes no s'hi sentissin identificats, o, encara pitjor, que menysvaloressin la pròpia, davant del prestigi del model que vehiculaven els mèdia (Solà 1987: 158-169).

El cert és que les posicions "light" incidien en un problema real: l'ampliació de registres demanava més recursos que els que facilitava la interpretació restrictiva del model fabrià, tal com s'havia aplicat tradicionalment. Una altra qüestió és que aquests recursos haguessin de sortir — tots- d'una pretesa "llengua del carrer" o de les interferències del castellà, per parlar només de lèxic, que era l'aspecte fonamental. A més a més, les opcions més acostades a la llengua parlada que permetia la normativa fabriana ja eren adoptades per un bon nombre d'editorials, era ja un moviment perceptible; els "ligth" hi van donar forma i empenyien una mica més enllà ${ }^{20}$. Per altra banda, era impossible ignorar que la situació precària de la llengua no obeïa a problemes "lingüístics". De fet, no s'ha demostrat que el model de llengua del diari Avui fracassés perquè els lectors no l'entenien (qualsevol lector d'una llen-

20. Amb la introducció del català com a llengua vehicular a l'escola, moltes editorials es van plantejar el model de català que havien de fer servir per parlar de geografia, d'història, d'art... Evidentment, les orientacions (internes) de les editorials anaven en el mateix sentit que les propostes "ligth", dins del respecte a la normativa, és clar. 
gua de cultura sap que al diari no hi trobarà la "llengua del carrer"). I tampoc no s'ha demostrat que els lectors rebutgessin el Diari de Barcelona per les seves innovacions lingüístiques. Al darrere de l'èxit d'un diari també hi ha recursos econòmic, una bona direcció i bons periodistes!

El cas és que, al cap de vint anys més o menys de la polèmica, sembla evident que els partidaris de les posicions "ligth" han guanyat la partida, en el sentit que els mitjans audiovisuals han optat per la majoria de solucions que ells propugnaven, i — com hem dit més amunt— fins i tot l'IEC ha acceptat al seu diccionari normatiu moltes de les propostes lèxiques que defensaven. Perquè bàsicament es tractava d'això, de propostes lèxiques, d'ampliació del lèxic normatiu. Però les necessitats dels nous registres van molt més enllà del lèxic.

\subsection{Catalunya Ràdio}

El juny del 1983 es va encarregar a Ricard Fité l'elaboració d'unes orientacions lingüístiques per a l'emissora, les Orientacions per a l'ús de la llengua a Catalunya Ràdio i RAC" (Casals 2001b), que desplega la filosofia "ligth", dins del respecte a la normativa: proscripció d'arcaismes, rellevància de la varietat central, consideració dels diferents registres radiofònics i adequació de la llengua a les característiques pròpies de la radiodifusió: claredat, concisió, expressivitat..

L'any anterior, el 1982, Francesc Vallverdú, que havia de ser màxim responsable de la Comissió de Normalització Lingüística de TVE, havia publicat Elocució i ortologia catalanes (per a ús de locutors de ràdio i televisió), on, a part de fer les primeres consideracions sobre el tipus d'elocució que requereix el mitjà, una qüestió que en general no ha estat gaire tractada en català, manifestava la dificultat de parlar d'un estàndard oral del català, al mateix nivell que es parlava d'estàndard escrit. Deia que "Malgrat que el dialecte central té més pes cultural i social que les altres varietats, no s'ha arribat a imposar com a estàndard oral". I hi afegia: "La majoria de lingüistes i sociolingüistes coincideixen a no acceptar un model ortològic de tipus castellà o francès, i recomanen models com l'alemany, el rus o l'italià, en què les pronunciacions dialectals són respectades" (Vallverdú 1982: 16-17).

El 1990 l'IEC presenta una Proposta per a un estàndard oral de la llengua catalana I. Fonètica, en la qual opta per un model "polimòrfic i composicional", que permeti la participació en l'estàndard de les principals varietats dialectals. 


\subsection{Televisió de Catalunya}

Consta que pocs mesos abans de la inauguració de TV3 Ferran Toutain va encarregar-se d'elaborar unes propostes lingüístiques relatives al model de llengua (Paloma 1998: 7). L'autor hi distingia entre nivells de llenguatge i registres, i proposava un estàndard obert. Recomanava acostar-se a la llengua parlada, mantenint-se, però, dins de la normativa, i evitar arcaismes i dialectalismes en pro de les formes més habituals. Criticava també la llengua de la televisió de Miramar (RTVE) per l'abús de construccions enfarfegades i estranyes a la llengua corrent. Ja en aquesta primera proposta es defensaven formes lèxiques que no figuraven al diccionari normatiu, com cuidar ('tenir cura'), entregar ('lliurar'), etc., la majoria de les quals hi han acabat sent recollides

Un dels problemes importants amb què es va trobar la llengua de la televisió (la de la ràdio, en menor mesura) és el dels registres anomenats "col·loquials" o "familiars", en les sèries de producció aliena o en el doblatge de les pel-lícules estrangeres: ¿quin havia de ser el paper, per exemple, de les paraules grolleres? A partir de 1985, la Comissió de normalització lingüística s'ha anat pronunciant explícitament sobre l'adequació o no per a determinats registres de mots com puta, marica, cabró, mamó, cardar o follar (que només s'havien de fer servir excepcionalment), enfront de collonut, collonada, conya, cabronada, etc., que podien fer-se servir quan l'original tingués "un to molt descordat". El tema de l'adequació al registre de determinats mots, grollers o collloquials, molts d'ells no normatius, continuaria preocupant els assessors lingüístics de TV3 (Paloma 1998) ${ }^{21}$.

Aquesta preocupació estava justificada, perquè el problema era real i evident, i perquè aquestes qüestions, les de lèxic, juntament amb les de fonètica (hi havia crítiques a la fonètica acastellanada o xava d'alguns presentadors), eren les queixes més freqüents dels televidents.

Podem dir que, amb el pas del temps, la tolerància s'ha anat eixamplant, tant a la ràdio com a la televisió. En part perquè hi ha més emissores —i més programes-, i lògicament no es pot mantenir perpètuament un exèrcit d'assessors lingüístics (és molt car!) ${ }^{22}$. En els estudis que hem anat realitzant

21. L'any 2005 es va inaugurar el portal lingüístic "ésadir" (http://esadir.com), que recull tota la informació lingüística acumulada des del 1983.

22. Al 1989 hi havia sis assessors lingüistics en els informatius, un per als esports i tres per a producció interna. A producció aliena hi va haver quinze assessors fins el 1986, en què es va reorganitzar el departament i es va externalitzar el doblatge. Els estudis que volen treballar per a TV3 s'han d'homologar i contracten els seus professionals, i la Comissió de normalització lingüística pot rebutjar un doblatge que consideri defectuós. 
regularment en el grup Llengua i Mèdia hem pogut comprovar aquesta "obertura", sobretot en les sèries de producció pròpia (programes de Buenafuente, de La Cubana, Jet lag, Plats bruts, Porca Misèria, etc.), en les quals apareixen tota mena d'interferències, sobretot en la llengua col-loquial.

I és que aquest és un dels problemes no resolts: el dels registres col-loquials. A vegades els policies i els delinqüents d'una pel-lícula americana parlen, en la versió doblada, com si haguessin estudiat a Harvard. A Televisió de Catalunya s'ha treballat força en el tema ${ }^{23}$, però és lògic que una empresa de doblatge no es vulgui arriscar a utilitzar recursos no normatius, si no té instruccions explícites sobre el particular.

Les alternatives en aquest cas són: utilitzar el col-loquial interferit pel castellà (és el recurs utilitzat per sèries i programes de producció pròpia), fer servir recursos genuïns (però que poden sonar estranys, poc sentits), inventar-se'n de nous, perquè la llengua de la ficció televisiva és, també, ficció.

\subsection{El cas de les retransmissions de futbol en català: un exemple innovador}

Les retransmissions de futbol en català han sigut un dels èxits més aclaparadors de la radiofonia catalana. Parteixen d'una iniciativa de Joaquim Maria Puyal, periodista de Radio Barcelona, que collaborava amb José Maria García en programes esportius de la cadena Ser. Puyal fa la proposta a la direcció de l'emissora, que l'accepta amb escepticisme ${ }^{24}$ : fins aleshores totes les retransmissions futbolístiques (i d'altres esports) s'havien fet en castellà. Li posen una condició: que busqui patrocinadors. Puyal en troba un de bo, la Caixa.

A continuació es tractava d'"inventar" un registre radiofònic fins aleshores inexistent en català, i és clar que el català literari no podia subministrar gaire recursos. Però Puyal, amb la colllaboració de Jordi Mir, assessor lingüístic del Futbol Club Barcelona, va fer una tasca de recerca de lèxic i fraseologia en la premsa esportiva catalana d'abans de la guerra, en la llengua popular dels aficionats... i també va usar la imaginació. Va defugir la solució fàcil: calcar el llenguatge esportiu castellà.

I els resultats van ser espectaculars. Al cap de 30 anys el programa que dirigeix Puyal, "Futbol en català", —que ara s'emet per Catalunya Ràdio—-

23. Hi ha un recull de textos publicats, Criteris lingüístics sobre traducció i doblatge. Ed. 62. Barcelona 1997.

24. Sembla que un directiu de l'emissora va demanar "pero, ¿ya lo entenderá alguien?" (Franquet 2001: 217). 
continua sent líder d'audiència en la seva franja horària (el segueixen més del 50\% dels aficionats que escolten la retransmissió del partit del Barça). La qualitat lingüística de l'espai és bona i ha (re)creat un lèxic i una fraseologia esportius que els radiooients han fet seus. I no solament això: Puyal ha creat un estil, i la majoria d'emissores locals i estatals que emeten per a Catalunya també retransmeten els partits en català.

\section{CONCLUSIONS I COMENTARI FINAL}

La incorporació del català als mitjans de comunicació es realitza de forma lenta i poc significativa en termes d'audiència, fins a l'etapa democràtica. El model al qual recorren les primeres retransmissions es basa en la llengua literària, en el model reduccionista de la normativa fabriana que havien anat aplicant els correctors en els temps difícils de la dictadura.

Quan la irrupció de la llengua en els mitjans audiovisuals és significativa, amb moltes hores de programació i tota la diversitat de gèneres que comporta, el model fa fallida. Els joves assessors lingüístics partidaris d'una "llengua moderna" intervindran decisivament en l'elaboració del nou model, que sobretot es caracteritza per una major obertura a la llengua colloquial i que incorpora castellanismes i formes no acceptades per la normativa.

De totes maneres, el problema que per al català representa la pressió mediàtica aclaparadora del castellà no es resol simplement obrint les portes a les interferències. Les exigències que plantegen els nous registres es poden cobrir calcant les solucions dels altres o de manera creativa, com en el cas que hem vist de "Futbol en català".

Considerant, com apuntàvem abans, que el mitjà és també creador de realitat, en tant que creador de ficció, s'ha abusat del recurs al "llenguatge del carrer". Perquè, ¿què és el llenguatge del carrer? ¿de quin carrer parlem?

Una de les característiques de la llengua col-loquial, tan mal descrita en general, és que té peculiaritats lligades a factors socials, geogràfics, professionals... en una paraula, no és mai una llengua uniforme.

D'altra banda, són precisament els mitjans de comunicació els que fan aparèixer un col-loquial "general", en què l'audiència es pot sentir reconeguda. Per posar un parell d'exemples concrets: a les sèries costumistes de les cadenes espanyoles hi ha molta presència de la llengua del carrer. Però la popularització d'expressions com "va a ser que sî" o "hasta aquí puedo leer" o tantes altres que han donat a conèixer les sèries o els consursos televisius, es produeix perquè el mitjà les difon! Tant se val que hagin sortit d'un carrer de debò com del magí del guionista. 
La difusió de lèxic o d'expressions terminològiques és una característica dels mèdia. Els meteoròlegs de TV $3,{ }^{25}$ per exemple, han popularitzat expressions com "cap de fibló" ('tornado'), per no parlar de les "depressions", de la "gota freda", etc. En resum: no podem menysprear la creativitat, el potencial innovador dels llenguatge dels mitjans de comunicació, en cap registre.

REFERÈNCIES BIBLIOGRÀFIQUES

Balcells, Albert \& Enric Pujol (2002): Història de l'Institut d'Estudis Catalans (1907-1942). Barcelona: Institut d'Estudis Catalans, Afers.

Benet, Josep (1995): L'intent franquista de genocidi cultural contra Catalunya. Barcelona: Publicacions de l'Abadia de Montserrat.

Casals i Martorell, Daniel (2001a): "Les polèmiques entre lights $i$ heavies $i$ les seves repercussions en l'elaboració dels models lingüistics per als mitjans de comunicació de massa", in Miguel Angel Pradilla (ed.): Societat llengua i norma. A l'entorn de la normativització de la llengua catalana. Benicarló: Alambor, 127-162 .

Casals i Martorell, Daniel (2001b): "El primer llibre d'estil de les emissores radiofóniques de la Corporació Catalana de Ràdio i Televisió (I): Orientacions per a l'ús de la llengua a Catalunya Ràdio i RAC (1986)", Llengua E Literatura 12, 339-374.

Franquet i Calvet, Rosa (1986): Història de la radiodifusió a Catalunya (Del naixement al franquisme). Barcelona: 62.

Franquet i Calvet, Rosa (2001): Història de la ràdio a Catalunya al segle XX (de la ràdio de galena a la ràdio difital). Barcelona: Generalitat de Catalunya.

Gabinet de Premsa de RTVE a Barcelona / Línea, Serveis de Comunicació Gràfica (1980): Breu història dels programes en català a RTVE. Barcelona: RTVE Barcelona.

Gregory, Michael \& Susanne Carroll (1978): Languages and situation. Language varieties and their social contexts. London: Routledge \& Keagan Paul.

Grup d'Estudis Catalans (1992): El barco fantasma. Barcelona: Llibres de l'Índex.

Institut d'Estudis Catalans (1990): Proposta per a un estàndard oral de la llengua catalana. I. Fonètica. Barcelona: IEC.

Lamuela, Xavier \& Josep Murgades (1984): Teoria de la llengua literària segons Fabra. Barcelona: Quaderns Crema.

25. Els programes meteorològics de TV3 són líders d'audiència a la cadena. 
López del Castillo, Lluís (1976): Llengua estandard i nivells de llenguatge. Barcelona: Laia.

Mir, Anna (2003): "Correctors, assessors, lingüistes: reflexió sobre el procés de revisió de textos escrits", Llengua \& Literatura 14, 211-237.

Munsó i Cabús, Joan et al. (1980): Breu història dels programes en català a RTVE. Barcelona: RTVE.

Paloma, David (1998): "Decisions internes sobre el model de llengua [de TV3]", in N. Faura; D. Paloma \& A. M. Torrent: La llengua de Televisió de Catalunya. Materials per a l'anàlisi. Bellaterra: Universitat Autònoma de Barcelona, 7-16.

Solà i Cortassa, Joan (1977): Del català incorrecte al català correcte. Història dels criteris de correcció lingüística. Barcelona: 62.

Solà i Cortassa, Joan (1987): L'obra de Pompeu Fabra. Barcelona: Teide, 158169.

Vallverdú, Francesc (1982): Elocució i ortologia catalanes (per a ús de locutors de ràdio i televisió). Barcelona: Jonc.

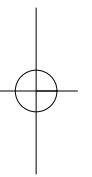

